\title{
ENDOVENOUS LASER ABLATION OF THE POPLITEAL FOSSA VEIN (THIERY VEIN)
}

Matvey Parikov1, Dmitry Slavin², Igor Kalitko³, Eugeniya Astafieva', Ekaterina Gavva1', Ucha Dolidze', Ivan Stepnov ${ }^{1}$

IInnovative Vascular Center, Saint-Petersburg, Russia

${ }^{2}$ Kazan State Medical Academy, Kazan, Russia

${ }^{3}$ Innovative Vascular Center, Moscow, Russia
ORIGINAL PAPER

Phlebological Review 2015; 23, 1: 9-13

DOl: $10.5114 /$ pr.2015.51626

Submitted: 22.12 .2014

Accepted: 26.04 .2015

\section{ADDRESS FOR CORRESPONDENCE}

Dr Matvey Parikov

Innovative Vascular Center

e-mail: parikow@mail.ru

\section{INTRODUCTION}

Popliteal fossa vein (PFV) perforates the muscular fascia to connect superficial veins with deep veins, namely, the popliteal vein [1-3]. The prevalence of reflux in a PFV has varied between $8 \%$ in patients with non-saphenous venous reflux [1] and $1 \%$ in patients with primary varicose veins. Twisted cluster-like varicose veins on the back side of the calf in popliteal fossa are specific for PFV insufficiency cases (Fig. 1). The subfascial part of the PFV is usually heavily twisted, enlarged, and has complex course [3]. Also it is important to note that this course of the PFV provides it with close contact with popliteal fossa nerves (sural and peroneal) (Fig. 2). The classic therapeutic approach for PFV insufficiency is removal of the subfascial part through an incision in the popliteal area and mini phlebectomy of the epifascial part, which may lead to the cosmetic displeasure because of incision marks and may also be accompanied by technical challenges in the divi- sion of the PFV junction and risk of injury to nerves [4, 5]. Foam-form sclerotherapy is an alternative treatment. However, it is necessary to take into account two concepts. First, injection of the sclerosant near the popliteal fossa might cause a real risk of deep vein thrombosis (DVT), and second, considering the significant diameter of the PFV subfascial part, there is a high risk of recanalisation.

We have used endovenous laser ablation (EVLA) for the incompetent PFV since 2007 and have treated more than 70 patients with that pathology. In this study we analysed 40 cases that we performed from 2011 to 2013, studying the PFV anatomy and EVLA features with Slim fibre.

\section{MATERIAL AND METHODS}

From 2011 to 2013, among patients with a primary varicose veins, we revealed PFV insufficiency in $1.7 \%$ of all patients (40 patients, 40 legs). Females were 35 (87.5\%) and males were $5(12.5 \%)$. The average age was $46.82 \pm 12.07$ 


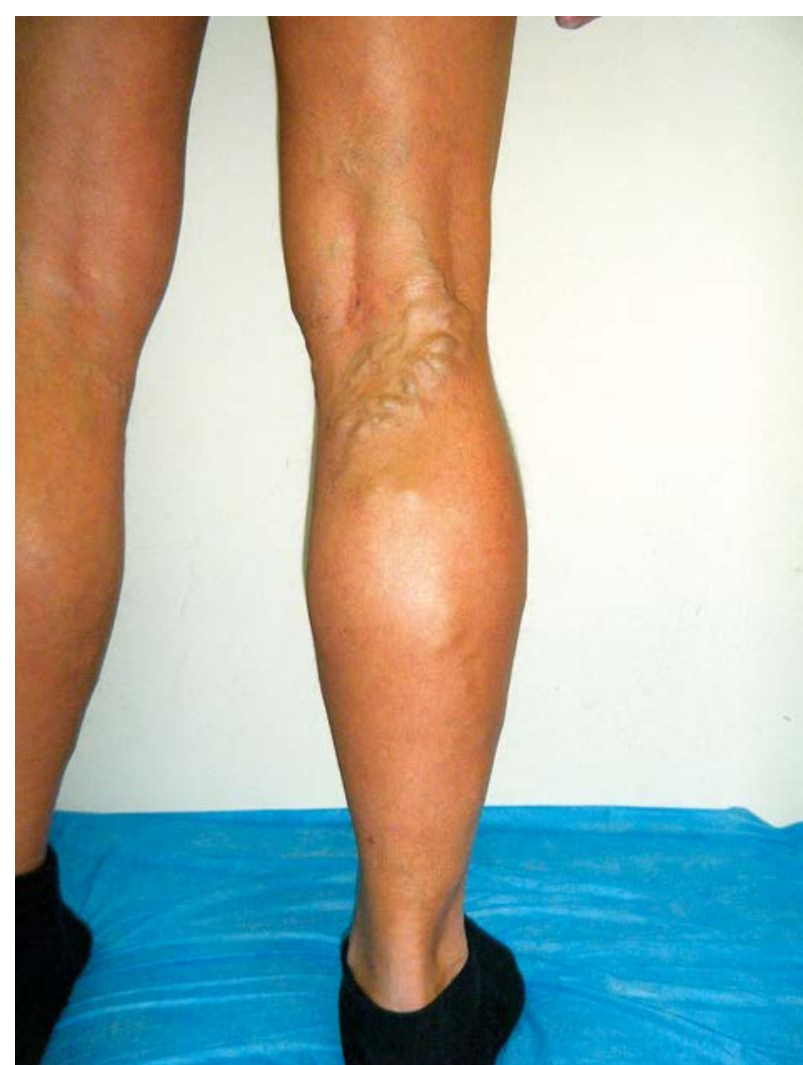

Fig. 1. Patient with typical incompetence of popliteal fossa vein

years (range 28-64 years). CEAP: C2 - 23 (57.5\%), C3 - 11 (27.5\%), C4 - 3 (7.5\%), C5 - 2 (5.0\%), and C6 - 1 (2.5\%). A duplex ultrasound (DUS) had been performed on an "Imagic Agile" (Kontron Medical, France) scanner, which provided an excellent opportunity to visualise the nerves. During the DUS we identified variations of the vein courses in popliteal fossa, its topographic and anatomical relations with nearby nerves, and puncture point for the EVLA PFV.

Endovenous laser ablation was performed on an ambulatory basis with a $1470 \mathrm{~nm}$ diode laser (Ceralas 15E Biolitec AG, Germany) and Slim radial fibres (Biolitec AG, Germany). The subfascial part of the PFV was punctured with a $16 \mathrm{G}$ intravenous cannula to introduce the slim radial fibre. Then a tumescent solution was injected. During tumescent anaesthesia (TA) the PFV was separated from tibial and peroneal nerves in this area. The final position of the laser fibre in the PFV after TA had been confirmed taking into consideration the location of popliteal vein and nerves. The average distance between the final position of the laser tip and the popliteal vein junction was $10-15 \mathrm{~mm}$ from the popliteal vein.

We performed EVLA in a continuous mode with 6-7 Watts power and constant reciprocating movements of the laser fibre to prevent carbonisation and sticking, to achieve energy 50-100 J/cm depending on the vein diameter. In three cases EVLA of GSV was also performed (7.5\%). In all cases after EVLA we per-

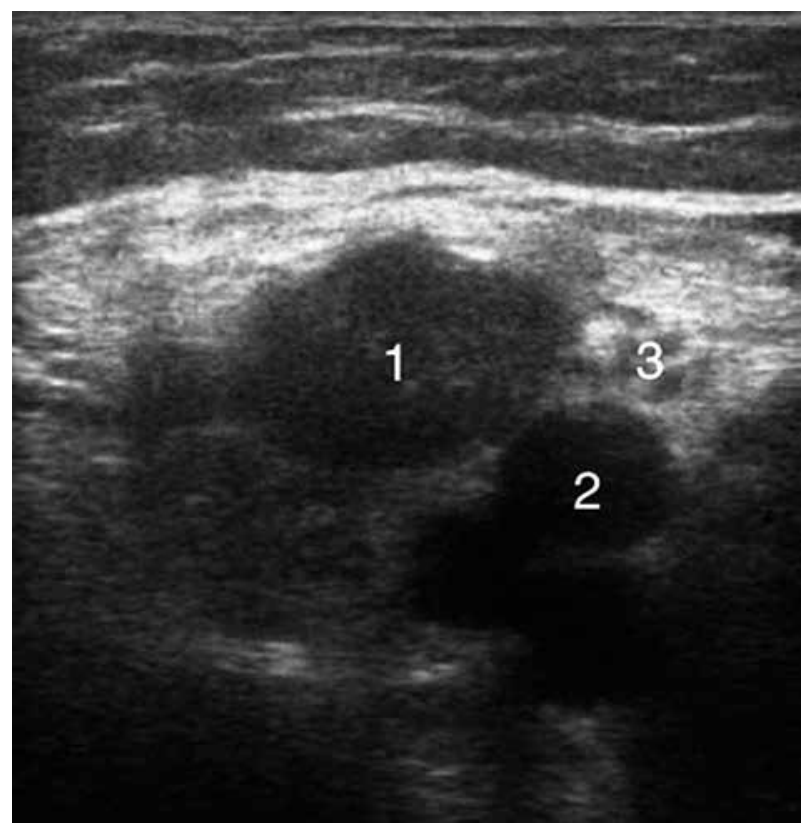

Fig. 2. US transverse view - relationship between popliteal fossa vein (1), popliteal vein (2) and nerve (3)

formed mini phlebectomy of the varicose tributaries using Varady's technic. In the postoperative period we recommended compression stockings for one week or longer and low-molecular-weight heparin (LMWH) in prophylactic doses for five days. The follow-up examinations were accomplished on the first day and after 1 week, and after 2 and 6 months. We assessed the DUS data (occlusion rate) and subjective symptoms such as the presence of neurological lesions and other side effects.

Russian clinical recommendations for the diagnosis and treatment of chronic venous disorders of lower limbs (2013) recommend EVLA for routine clinical practice and demonstrate its efficacy and safety. Retrospective analysis of the patients with EVLA of the popliteal fossa vein (Thiery vein) did not need acceptance by the Ethical Committee in the Russian Federation because it is an established and not experimental method. All of our patients had given their informed consent for these procedures.

\section{RESULTS}

According to the DUS, in 37 cases (92.5\%) isolated PFV insufficiency was revealed, and in another 3 cases (7.5\%) there were also simultaneous GSV insufficiency. In 3 cases $(7.5 \%)$ there were previous phlebectomies in the patient's anamnesis.

The DUS data allowed us to identify three different types of PFV anatomy. In $45 \%$ of cases $(n=18)$ we detected a straight course of the vein under the fascia ("Type 1" - a simple structure, Figs. 3, 4), which is the easiest for the puncture. In $35 \%$ of cases $(n=14)$ the vein had a com- 


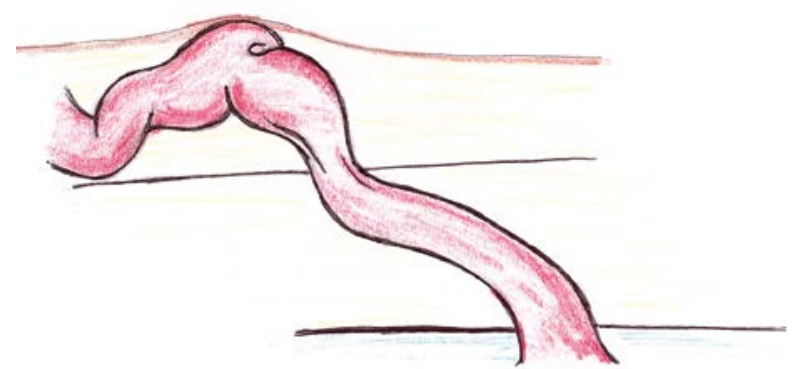

Fig. 3. First type of popliteal fossa vein

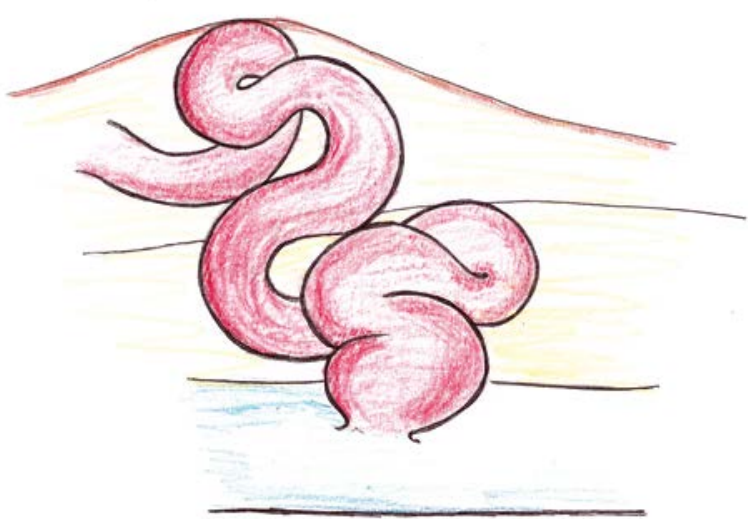

Fig. 5. Second type of popliteal fossa vein

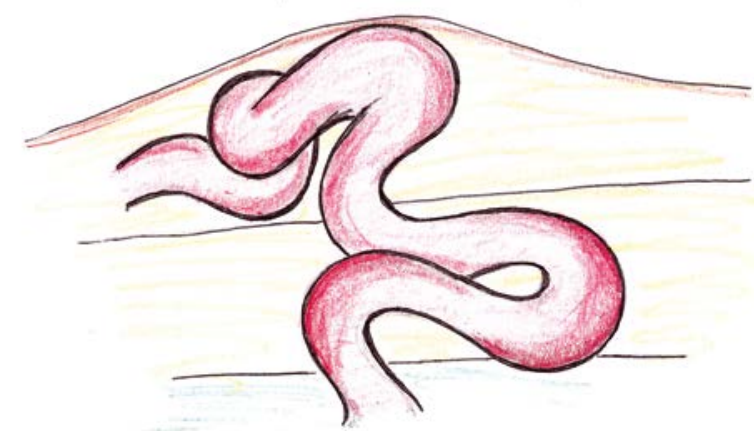

Fig. 7. Third type of popliteal fossa vein

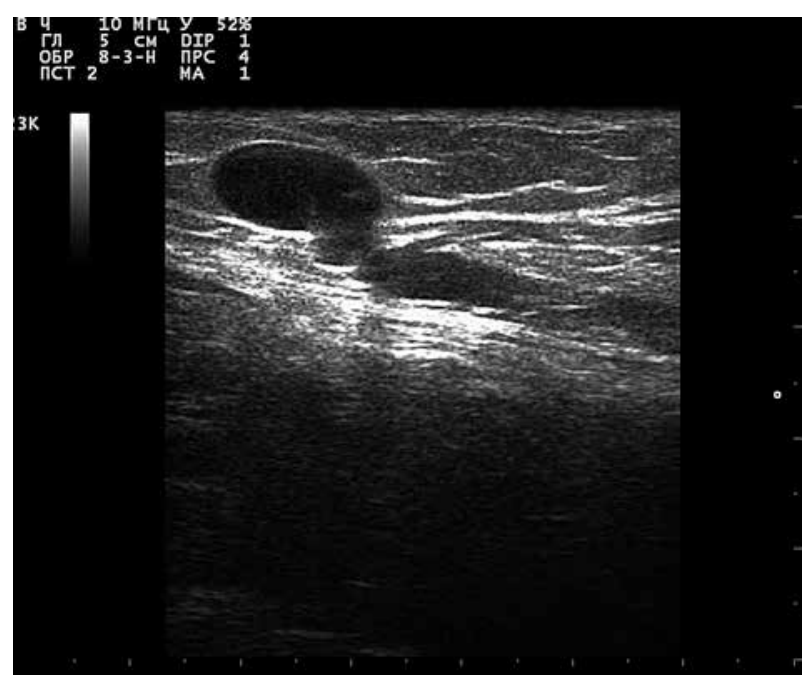

Fig. 4. US longitudinal view of first type of popliteal fossa vein

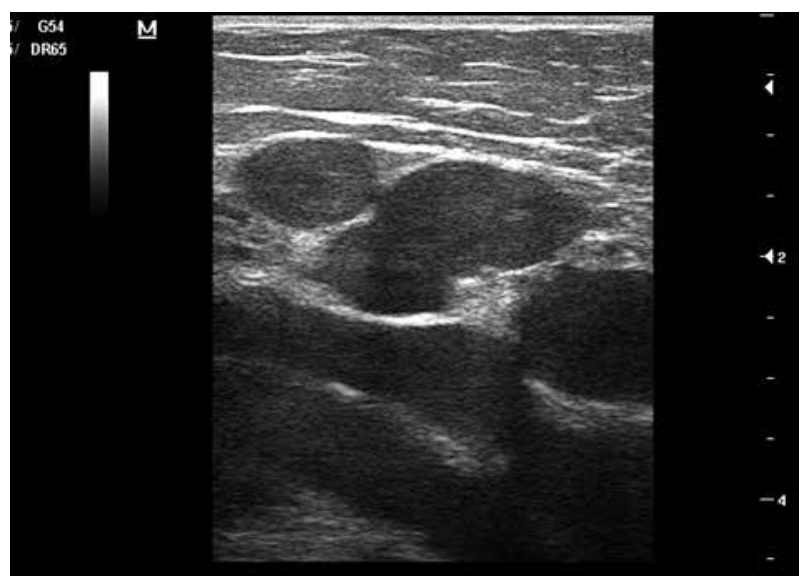

Fig. 6. US longitudinal view of second type of popliteal fossa vein

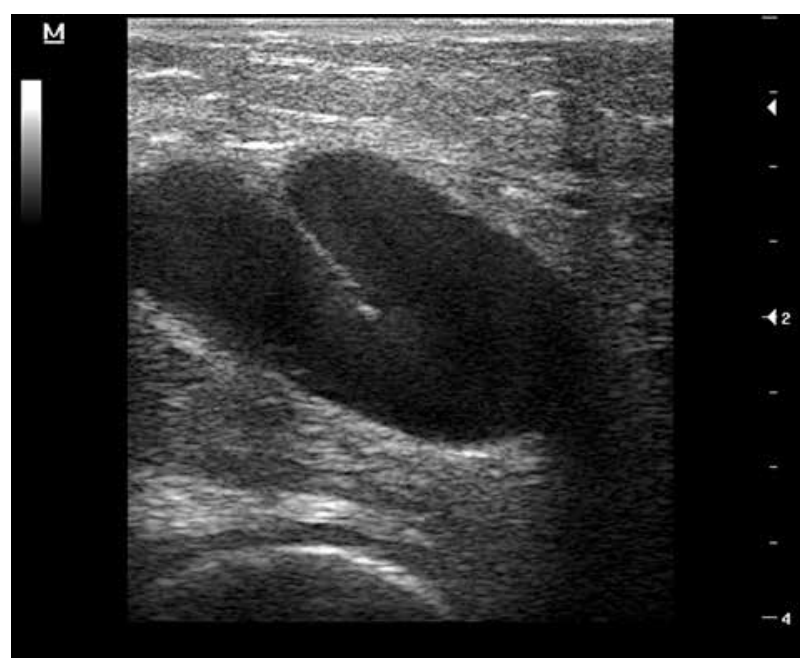

Fig. 8. US longitudinal view of third type of popliteal fossa vein 


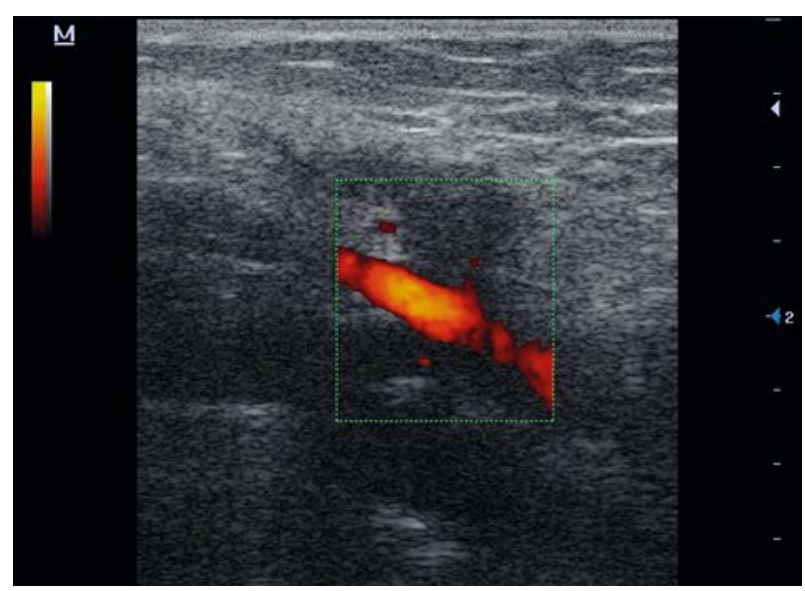

Fig. 9. Obliterated popliteal fossa vein after 1 month

plex structure resembling a tuber ("Type 2" - a complex tuber-like structure, Figs. 5, 6), which is the most difficult for the puncture and fibre positioning. And the third type was detected in $20 \%$ of cases $(n=8)$ and was characterised by loop-form veins ("Type 3" - a complex, looplike structure, Figs. 7, 8). Commonly in this type of the structure the part of the loop closest to the popliteal vein had reversed direction. In all cases the PFV joined the popliteal vein directly. We did not reveal the valves in the junction of PFV with the popliteal vein.

The mean length of the subfascial part was $3.32 \pm 1.06$ $\mathrm{cm}$ (range 2-5 cm), mean diameter - $6.86 \pm 3.44 \mathrm{~mm}$ (range $4-10 \mathrm{~mm}$ ). Thus the length of the subfascial part varied from 2 to $5 \mathrm{~cm}$, and the PFV had complex structure in $55 \%$ of cases.

The puncture of PFV for EVLA was successful in all patients. We did not observe haematomas in popliteal fossa. In 13 cases $(32.5 \%)$ the fibre position covered the entire length of the subfascial part. In 27 cases (67.5\%) the fibre had been positioned in the most enlarged parts of the PFV: in the proximal part of the PFV - 11 cases (27.5\%), middle part - 13 cases (32.5\%), and in 3 cases $(7.5 \%)$ in both the distal and middle parts. In all cases we could perform EVLA successfully.

The average time of the postoperative follow-up was $7.45 \pm 4.13$ months (range 2-24 months). We did not observe DVT, thrombus protrusion in to the popliteal vein, motor neurological disorders and haematomas, or rupture during the therapy. In one case $(2.5 \%)$ a minor temporary sensory paraesthesia in the popliteal area was revealed, which resolved unattended in two months. Primary PFV occlusion was achieved in $97.5 \%$ of cases $(n=39$, Fig. 9). In one case the partial occlusion of the vein was revealed on the first day follow up and an additional foam sclerotherapy was performed. In further follow up period, in $97.5 \%$ of cases $(n=39)$, ablation and obliteration of the PFV was achieved (Fig. 10), and in only one case (2.5\%) a recanalisation of the vein with diameter regression was discovered (the same patient with partial occlusion of the vein and additional sclerotherapy).

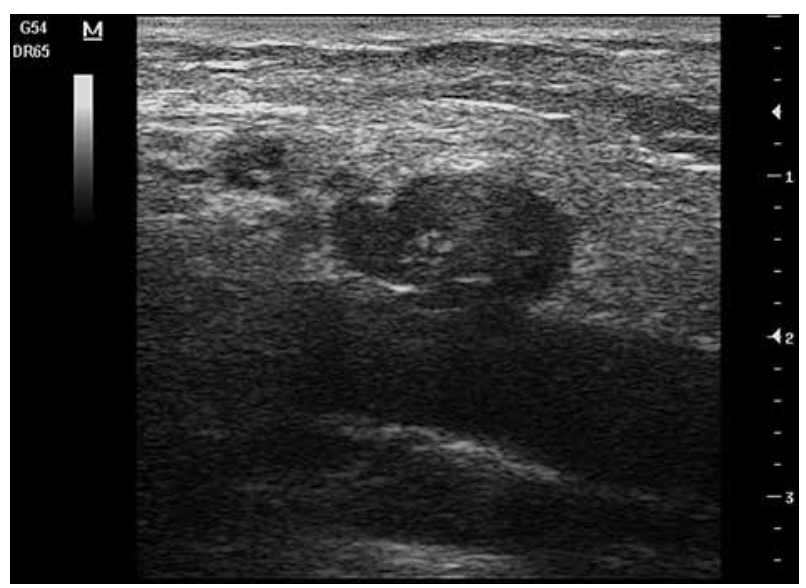

Fig. 10. Obliterated popliteal fossa vein after 6 months

\section{CONCLUSIONS}

Endovenous laser ablation is an effective and safe treatment of PFV insufficiency. A high success rate and a lack of neurological disorders make EVLA of the PFV a good alternative to traditional surgery.

\section{DISCUSSION}

Complex anatomy and potential risk of nerve damage prevent phlebologists from performing EVLA of PFV. Traditionally in cases with incompetent PFV they perform sclerotherapy or mini phlebectomy. Using high concentration foam-form sclerotherapy in the popliteal area may lead to deep vein thrombosis, while low concentrations may be ineffective. With mini phlebectomy it is impossible, without real incision, to ligate the subfascial part of PFV. Usually during mini phlebectomy the surgeon can find only the extra-fascial part of PFV and leaves a rather long part of the vein, which may cause phlebitis or even deep vein thrombosis. Also mini phlebectomy sometimes leads to ruptures of the veins and haematoma formation. There are no trials about the efficacy of these treatment methods for PFV. For sclerotherapy, for example, we only know about a 75\% success level for perforating veins $[7,8]$. For big and tortuous veins like PFV it is probably lower. Introduction of radial fibres extended the features of EVLA and made it more effective and safe [6]. The histological work of Spreafico et al. and our experimental model demonstrate another mechanism of action between the radial fibre and the vein wall, without contact damage, carbonisation, and perforations, compared to bare fibres $[9,10]$. Using radial fibres leads to a constant and homogenous coagulation effect. It means that EVLA with radial fibres is accompanied by minimal side effects and minimal impact on surrounding tissues, which is very important in such a complex anatomical place like the popliteal space. EVLA of GSV/SSV is more effective than sclerotherapy, and we suggest the same in laser treatment of incompetent PFV. 
The authors declare no conflict of interest.

\section{References}

1. García-Gimeno M., Rodríguez-Camarero S., Tagarro-Villalba S., Ramalle-Gomara E., González-González E., Arranz M.A., García D.L., Puerta C.V. Duplex mapping of 2036 primary varicose veins. J Vasc Surg 2009; 49: 681-689.

2. Creton D. 125 reinterventions for recurrent popliteal varicose veins after excision of the short saphenous vein. Anatomical and physiological hypotheses of the mechanism of recurrence. J Mal Vasc 1999; 24: 30-36.

3. Delis K.T., Knaggs A.L., Hobbs J.T., Vandendriessche M.A. The nonsaphenous vein of the popliteal fossa: prevalence, patterns of reflux, hemodynamic quantification, and clinical significance. J Vasc Surg 2006; 44: 611-619.

4. Thiery L. Surgical anatomy of the popliteal fossa. Phlebologie 1986; 39: 57-66.

5. Ricci S. Ambulatory Phlebectomy. Mosby, St. Louis 1995.

6. Zerweck C., von Hodenberg E., Knittel M., Zeller T., Schwarz $\mathrm{T}$. Endovenous laser ablation of varicose perforating veins with the 1470-nm diode laser using the radial fibre slim. Phlebology 2014; 29: 30-36.

7. Köroglu M., Eris H.N., Aktas A.R., Kayan M., Yeşildağ A., Cetin M., Parlak C., Gürses C., Akhan O. Endovenous laser ablation and foam sclerotherapy for varicose veins: does the presence of perforating vein insufficiency affect the treatment outcome? Acta Radiol 2011; 52: 278-284.

8. Gloviczki P., Comerota A.J., Dalsing M.C., Eklof B.G., Gillespie D.L., Gloviczki M.L., Lohr J.M., McLafferty R.B., Meissner M.H., Murad M.H., Padberg F.T., Pappas P.J., Passman M.A., Raffetto J.D., Vasquez M.A., Wakefield T.W.; Society for Vascular Surgery; American Venous Forum. The care of patients with varicose veins and associated chronic venous diseases: clinical practice guidelines of the Society for Vascular Surgery and the American Venous Forum. J Vasc Surg 2011; 53 (5 Suppl): $2 \mathrm{~S}-48 \mathrm{~S}$.

9. Spreafico G., Giordano R., Piccioli A., et al. Histological damage of saphenous venous wall treated in vivo with radial fiber and $1470 \mathrm{~nm}$ diode laser. J Vasc Endovasc Surg 2011; 18: 1-2.

10. Parikov M., Slavin D., Chugunov A. Possibilities of a new in vivo model for the study of the impact of laser energy on the venous wall at endovasal laser obliteration of the great saphenous vein. Practical medicine 05 (13) Pulmonology. Antimicrobial therapy. 